\title{
CYTOGENETIC ANALYSIS OF DOWN SYNDROME
}

\author{
G.S.Kadakol ${ }^{1}$, Ishwar Bagoji ${ }^{2}$, S V Patil ${ }^{3}$, R S Bulagouda ${ }^{1}$ \\ ${ }^{1}$ Genetics Laboratory, ${ }^{2}$ Department of Anatomy, ${ }^{3}$ Department of Paediatrics, \\ BLDE (Deemed to be) University, Shri B M Patil Medical College, Hospital \& Research Center, \\ Vijayapur 586103, Karnataka, India.
}

\begin{abstract}
Objective: Down syndrome is a common genetic disease, diagnosed with congenital malformation/mental retardation. Down syndrome occurs in all races \& economic levels. It is caused by third copy of chromosome 21 , there are there forms of DS. Simple Trisomy 21, Translocation Trisomy and Mosaic Trisomy. The aim of the study is to know cause of Down syndrome. Chromosomal analysis was carried out by $\mathrm{G}$ banding technique. Materials and Methods: $1 \mathrm{ml}$ of peripheral blood samples were collected in Out Patient Department of pediatrics and Cytogenetic analysis was performed. Results: Out of 28, 3 female cases, 2 male cases were Down syndrome, All the 5 cases were free trisomy 21, which is common type of Down syndrome; we have not identified Robertsonian translocation and mosaic type of DS. Conclusion: The present analysis shows that genetic risk factors are responsible for the incidence of Down syndrome.
\end{abstract}

Keywords: Down syndrome; North Karnataka; Prevalence; G-banded Karyotype.

\section{INTRODUCTION}

Down syndrome common chromosomal disorder, related with multiple congenital anomalies with mental retardation in the new borns. Incidence of Down syndrome varies from 1 in 600 to 1 in 1000 in live born infants $[1,2]$. In India, incidence of Down syndrome is 1 in 1250 [1].

By the Cytogenetic Analysis the presence of the extra 21 in DS has been classified free Trisomy 21, translocation trisomy 21 and mosaic trisomy 21 [3]. Free trisomy 21 is the most common variety, seen in $95 \%$ cases and occurs due to paternal meiotic non disjunction [1]. 2 to $4 \%$ showed a Robertsonian translocation and 1 to $3 \%$ showed mosaicism.

The clinical features are important for an early diagnosis to reduce morbidity and mortality. Apart from karyotype most characteristic features are mental retardation, congenital heart defects, facial features and in some cases developing AML at later stage [4].

The oral motor approached activities are effective in enhancing the feeding performance among children with Down's syndrome. It was also found that the therapy protocol has a greater effect in reducing tongue thrust thereby improving oral functional skills [5].

The extra chromosome 21 is translocated to the acrocentric chromosome of D group (Chromosome 13, 14, 15) or G group (Chromosome 21, 22). Such translocations are usually Robertsonian in type [1]. Non homologous Robertsonian translocation between chromosome 14

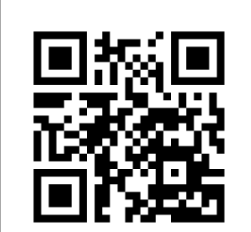

DOI: $10.31878 / \mathrm{ijcbr} .2018 .51 .10$

eISSN: 2395-0471

pISSN: 2521-0394 and 21 [rob $(14 q ; 21 q)]$ is the most common type while homologous Robertsonian translocation between chromosome 21 and $21[\operatorname{rob}(21 \mathrm{q} ; 21 \mathrm{q})]$ is the second most common type[6].Translocation Down Syndrome can be inherited from carrier parents [7].

Down syndrome occurs in people of all races and economic levels, though older women have an increased chance of having a child with Down syndrome. A 35 year old woman has about a one in 350 chance of conceiving a child with Down syndrome, and this chance increases gradually to 1 in 100 by age 40 . At age 45 the incidence becomes approximately 1 in 30 . The age of the mother does not seem to be linked to the risk of translocation. To study the effect of advanced maternal age on Down syndrome many hypotheses have been formulated. Initially Penrose identified that advanced maternal age as risk for Down syndrome birth [8].

The relation of advanced maternal age to an increased risk of DS has been well documented. In addition, maternal risk other than maternal age for DS births is clearly includes genetic and other risk factors in few published studies. With regard to genetic factor, Coppode et al. [9] has studied the role of methionine synthase reductase (MTRR), G-polymorphism as maternal risk factor for birth of DS in Caucasian women. Genetic polymorphism of MTHFR C677T, MTHFR A1298C in association with serum and RBC folate and serum homocysteine on maternal risk factor of Down syndrome [10]. On the other hand, Shalaby [11] explained other risk factors such as consanguinity, drug and environmental toxins and reproductive functions for increase incidences of DS. Karyotyping analysis were used in both human \& Plant cells to determine the structural changes in chromosomes [12].By the Karyotyping analysis chromosomal rearrangements can be seen in Infertility cases [13].

North Karnataka with its unique culture, customs and socio demographic factors is conductive to the occur-

Correspondence: Dr. R.S. Bulagouda, Department of Anatomy, Genetics Laboratory, BLDE (DU) Shri B M Patil

Medical College, Hospital \& Research Center, Vijayapur 586103, Karnataka. E-mail: nandhish.kadakol@gmail.com

(C) Authors; 2019. International Journal of Clinical and Biomedical Research, Sumathi Publications.

This is an Open Access article which permits unrestricted non-commercial use, provided the original work is properly cited. 
rence of different genetic disorders including population growth, demographic pattern, occupational shifts with high proportion of individuals engaged in sedentary lifestyle and substantially higher proportion of preobese and obese individuals. Consanguineous marriage is a traditional practice in many communities around the world. By keeping these points, in this study an attempt was made to trace out the role of in Down syndrome in north Karnataka population through Karyotyping Analysis.

\section{MATERIALS AND METHODS}

Study design: An observational descriptive study

Ethics approval: Study was approved by the institutional ethics committee and informed consent was taken from the parents.

Study location: Genetics laboratory, department of Anatomy, BLDE (DU), Karnataka

Study period: The study was carried from June 2016 to January 2017.

Inclusion criteria: All the participants were taken from our hospital, children's of age 0-5 years. Down Syndrome cases were recruited in our study .

Exclusion criteria: Other congenital defects and CHD cases as well as patients from other hospitals were excluded from the study.

Sample size: The present study subjected total of Twenty eight pediatric patients, with the age group of 3 to 120 days old out of which 12 were female and 16 were male.[4]

\section{Methodology:}

For Cytogenetic analysis we collected $1 \mathrm{ml}$ peripheral blood samples from Out Patient Pediatric department. Karyotyping was carried out for peripheral lymphocytes, cultured from peripheral blood and stained with Giemsa stain as per the Standard Operating Protocol. Olympus Trinocular Research Florescent In Situ Hybridization (FISH) with Applied Spectral Imaging Karyotyping System (Manufacturer name: Olympus, Japan; model: CH20i) was also used during the study. 20-40 spreads were analyzed for each case. The slides were analyzed for detection of chromosomal abnormality for Down syndrome (Trisomy 21).

\section{RESULTS}

A total of 28 clinically suspected cases were referred to our genetics laboratory for cytogenetic analysis. Of which 5 cases were found confirmed DS. The rest 23 cases were found to be other chromosomal anomalies. The maternal age of mother of DS patients are not advanced as shown I $\mathrm{n}$ (Table 1). The age of all DS patients were calculated and it was found to be 3 days to 4 months as shown in (Table2). Descriptive Statistics shows age mother with age DS patients in terms of standard deviation mother age will be $0.64 \&$ patients will be 24.6 (Table 3). Proportion rate of Down syndrome is $18 \%$, other syndrome will be $82 \%$ (Table4).All these cases were found to be free trisomy form (Figure 1).
Table 1. Distribution of patients according to Age of mothers

\begin{tabular}{l|l|l}
\hline $\begin{array}{l}\text { Age } \\
\text { Years }\end{array}$ & Frequency & Percent \\
\hline 24 & 1 & 3.6 \\
\hline 25 & 13 & 46.4 \\
\hline 26 & 13 & 46.4 \\
\hline 27 & 1 & 3.6 \\
\hline Total & 28 & 100.0 \\
\hline
\end{tabular}

Table 2. Distribution of patients according to Age of Infants

\begin{tabular}{l|l|l}
\hline Days & Frequency & Percent \\
\hline 7 & 10 & 36 \\
\hline $8-14$ & 6 & 21 \\
\hline $14-21$ & 2 & 7 \\
\hline $22-30$ & 4 & 14 \\
30 & 6 & 21 \\
\hline Total & 28 & 100.0 \\
\hline
\end{tabular}

Table 3. Descriptive Statistics.

\begin{tabular}{l|l|l|l|l}
\hline Age & N & Minimum & Max & Mean \\
\hline $\begin{array}{l}\text { Age of } \\
\text { Mothers }\end{array}$ & 28 & 24 & 27 & $25.5 \pm 0.64$ \\
\hline $\begin{array}{l}\text { Age of } \\
\text { infants }\end{array}$ & 28 & 3 & 120 & $20.7 \pm 24.6$ \\
\hline
\end{tabular}

Table 4. Proportion of Down syndrome

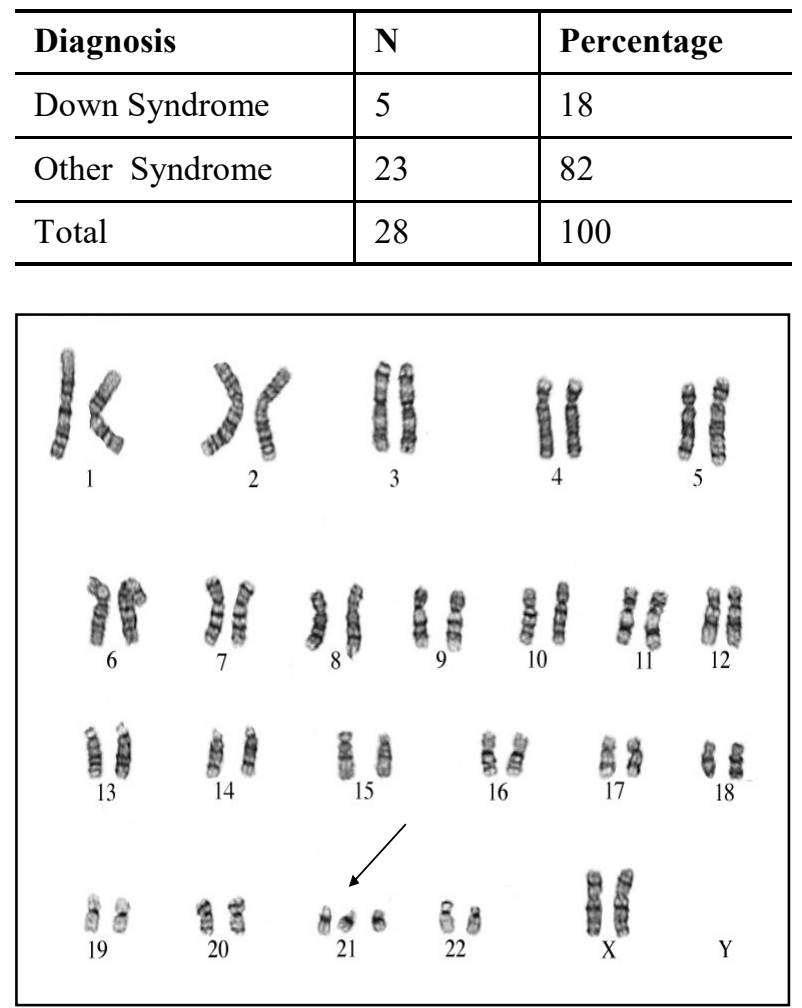

Figure 1. Down syndrome with free 21 normal trisomy female $(47 \mathrm{XX})$ 


\section{DISCUSSION}

Down syndrome has a prevalence of one in 500 to one in 1,000 live births, due to disorder of development arising from incomplete embryogenesis as a result of an additional chromosome 21 copy in the karyotype. This extra chromosome is derived from an over-expression of genetic material due to a tripling of the number of genes. This phenomenon produces structural and functional disorders of the all the systems of the body [14]. There are three forms of DS namely simple trisomy, Mosaic trisomy and translocation trisomy. Karyotype analysis of our study finds only the simple trisomy, in which a form of faulty division of reproductive cell (generally occurring during $1^{\text {st }}$ or $2^{\text {nd }}$ meiotic division) prior to or at conception that results in an embryo with three copies of chromosome 21. As the embryo develops, the extra chromosome is replicated in every cell of the body. The parental and the meiotic/mitotic origin of the additional chromosome 21 could be determined in the early 1990's with the help of DNA markers [15]. Simple Trisomy 21 in fact constitutes the most common form of DS in children and occurs at rates of $90-95 \%$. Karyotype for female are 47, XX, +21 and 47, XY, +21 for male [15].

Translocation involves transferring a chromosome fragment to centromere of another acrocentric chromosome. In DS such translocation occurs between chromosomes 14 and 21 which occur at rates of 5-6\% of all DS cases. The karyotype for female are 46, XX, der $(21 ; 21),+21$ or $46, \mathrm{XX}$, der $(14 ; 21),+21$ and for male $46, \mathrm{XY}$, der $(21 ; 21),+21$ or $46, X Y, \operatorname{der}(14 ; 21),+21[15]$.

A seldom form of DS is a condition known as mosaicism, which accounts for only $1-2 \%$ of all cases of full trisomy 21 DS Mosaicism characterized by the nondisjunction of chromosome 21 takes place in one of the initial cell divisions after fertilization, resulting in a mixture of two types of cells in the body, some with 46 and some with 47 chromosomes. The physical features of Down's may be milder in individuals with mosaicism trisomy 21 , especially if the proportion of normal cells is large [16]. All diagnosed cases were reported in our study were having confirmed DS in north Karnataka region. The frequency of free trisomy reported in the present study is most common seen which is in accordance with earlier reports $[17,18,19]$. Other studies revealed that advanced paternal age combined with advanced maternal age significantly influences the incidences of DS [20].However, earlier studies in the world reports regarding the maternal and paternal ages that increases the risk of chromosomal aneuploidy [21]. Present study shows that the overall female ratio was more compared to male. Other studies reported that excess of males appears to be universal and reported in literature from all over the world. Present study Translocation trisomy $21 \&$ mosaic 21 were not observed. Translocation and mosaic which are unique in nature as compared to previous studies [18].

There were reports of older maternal age having DS in previous studies from different countries [22, 23]. On the other hand, few studies have also reported incidences of DS to a much young maternal age [17, 24].In our study revealed that incidences of DS is young maternal age.

Several studies have been done on incidence of DS, but a complete understanding of the cause is yet to be ascertained. Risk factors of DS unlike maternal age, recently Coppode et al. [9] have suggested folate polymorphism as genetic risk factor for birth of DS child in Caucasian women and Shalaby [11] reported consanguinity, drug and environmental toxins as other risk factors.

\section{CONCLUSION}

In the Present study Genetic factors \& maternal age are higher incidences in Down syndrome. In the present study conclude that free trisomy 21 is most common type Down syndrome chromosomal abnormality in this region.

Suggestions: It is important to educate \& create awareness to family at high risk occurrence to go for screening during pregnancy. It is necessary to adopt appropriate prevention strategies and interventions in high risk individuals to curb the growing epidemic of Down syndrome. Innovative community outreach programmes need to be designed and implemented for creating awareness, early screening and treatment of Down syndrome.

Limitation of study: India is known for high degree of inbreeding with its heterogynous population. This makes it necessary to screen a large number of patients perhaps within each group in order to get a true picture of Down syndrome. In order to find out the prevalence of any risk factors, a large number of families need to be investigated

Acknowledgement: Authors are thankful to family members for their participation in this study. We are also thankful to Department of Pediatrics \& Department of Anatomy, our Hon,ble Vice Chancellor Dr M S Biradar BLDE (DU) Shri B M Patil Medical College Hospital \&Research Centre, Registrar, and Principal for their guidance, support for this study.

\section{Conflict of Interest: Declared none}

\section{REFERENCE}

1. Jayalakshamma MM, Amudha S, Tilak P, Devi R,Rajangam S. Cytogenetic Analysis in DownSyndrome. Int J Hum Genet 2010; 10:95-99

2. Amayreh W, Al Qaqa K, Ali AH, Issa K. Clinicaland Cytogenetic Profile of Down Syndrome atKing Hussein Medical Centre. JRMS 2012; 19:1418.

3. Kolgeci S, Kolgeci J, Azemi M, Shala-Beqiraj R, Gashi Z, Sopjani M. Cytogenetic Study in Childrenwith Down Syndrome Among Kosova Albanian Population Between 2000 and 2010. Mat Soc Med 2013; 25: 131-5.

4. Podder G, De A, Adhikari A, Halder A,Banerjee J, De M. Assessment of Down syndrome patients in west Bengal, India.Pacific J Med Sci. 2012;10(2):28 $-35$

5. Ramanathan Asha, Mot Alli . A Study To assess The Effectiveness of Oro-Motor and Behavioral Approach to Reduce Tongue Thrust in Children with Down's Syndrome. International Journal of Pharma and Bio Sciences. 2016; 7(4): 332 - 5. 
6. Earle E, Shaffer LG, Kalitsis P, McQuillan C, Dale S. Identification of DNA sequences flanking the breakpoint of human $\mathrm{t}$ (14q21q). Robertsonian translocations. American Journal of Human Genetics.1992;50:717-24.

7. Han JY, Choo KHA, Shaffer LG. MolecularCytogenetic characterization of 17 rob (13q14q) Robertsonian translocations by FISH - narrowingthe region containing the breakpoints. American Journal of Human Genetics. 1994;55: 960-7.

8. Penrose LS. The relative effect of paternal and maternal age in Mongolism. Journal of Genetics. 1933;27(2): 219-24.

9. Coppedè F1, Bosco P, Lorenzoni V, Denaro M, Anello G, Antonucci I, BaroneC, Stuppia L, Romano $\mathrm{C}$, Migliore L. The MTRR c.66A $>\mathrm{G}$ polymorphism and maternal risk of birth of a child with Downsyndrome in Caucasian women: a casecontrol study and a meta-analysis. Mol.Biol. Rep. 2014;41 (9):5571-83.

10. Pandey Sanjeev, Mohanty Pankaj, Polipalli Sunil and Kapoor Seema Genetic Polymorphisms of MTHFR (677t and 1298c) and Homocysteine Metabolism as Maternal risk factor for Down's syndrome Patients in North Indian Population. International Journal of Pharma and Bio Sciences. 2013;4 (2): $249-56$

11. Shalaby HMA. A study of new potential risk factors for Down syndrome in Upper Egypt. The Egypt J. Med. Human Genetics. 2011;12:15-19.

12. Panigrahy Suchitra KU, Jatawa S, Tiwari Archana. Modulatory Effect of Chenopodium Album Extract Against Cyclophosphamide Induced Genotoxicity Damage in Cultured Mammalian Cells. International Journal of Pharmacy and Pharmaceutical Sciences. 2012; 4(1):541-2.

13. Vaghasia Ketan K, Shah Nidhi D, Shah Parth S, Bhatt Vidhi M, Shah Sandip C, Rao Mandava V. Karyotypic Analysis of Chromosomal Polymorphism in Relation to Reproductive Failure. International Journal of Pharmacy and Pharmaceutical Sciences.2017;9(4):140-3

14. Dominika Mazurek, Joanna Wyka. down syndrome - genetic and nutritional aspects of accompanying disorders 2015;66(3):189-94.

15. Antonarakis SE, Lewis JG, Adelsberger PA, Petersen MB, Schinzel AA, Binkert F, Schmid W, et al Parental origin of the extra chromosome in trisomy 21 as indicated by analysis of DNA polymorphisms. N Engl J Med 1991;324: 872-6.

16. Mikkelsen, Down syndrome: Cytogenetical epidemiology Hereditas 1977;86,(1): 45-9

17. Malini SS, Ramchandra NB. Influence ofadvanced age of maternal grandmother onDown syndrome. BMC Med. Genet.2006;7: 4.

18. Kaur A, Singh J. Chromosomal abnormalities: Genetic disease burden inIndia. Int. J. Hum. Genet. 2010;10(1-3):1-14.
19. Sheth F, Rao S, Desai M, Vin J, Sheth J.Cytogenatic analysis of Down syndrome inGujarat. Indian Peditrics. 2007;44:774-7.

20. Fisch H, Hyun G, Golden R, Hensle TW,Olsson CA, Liberson GL. The influence of paternal age on Down syndrome. J Urol.2003;169:2275-8.

21. Sherman SL, Freeman SB, Allen EG, Lamb NE. Risk factors for non-disjunction of trisomy 21 Cytogenetics Genome Res. 2005;111(3-4):273-80.

22. Azman BZ, Ankathil R, Siti Mariam I,Suhaida MA, Norhashimah M, Tarmizi AB, Nor Atifah MA, Kannan TP, Zilfalil BA. Cytogenetic and clinical profile of Down Syndrome in Northeast Malaysia.Singapore Med J. 2007;48:550-4.

23. Jaouad IC, Cherkaoni DS, Sbiti A, Natiq A,Elkerch F, Sefiani A. Cytogenetic andepidemiological profiles of Down syndromein Moroccan Population: A report of 852cases. Singapore Med J. 2010;51:1336.

24. Chandra N, Cyril C, Lakshminarayana P,Nallasivam P, Ramesh A, Gopinath PM,et al. Cytogenetic evaluation of DownSyndrome: A review of 1020 referralcases. Int. J. Humn. Genetics. 2010;10:87-93. 